\title{
Child And Adolescent Patients attending Psychiatric Out-Patient Department
}

\author{
Poudel R', Shah $\mathrm{S}^{2}$, Gupta $\mathrm{U}^{3}$
}

\begin{abstract}
1. Lecturer, Department of Psychiatry, NGMC, Kohalpur, Nepal 2. Assistant Professor, Department Of Psychiatry, UCMS, Bhairahawa, Rupandehi, Nepal 3. Consultant Psychiatrist, Mangal Clinic, Jaunpur, UP, India.
\end{abstract}

E-mail *Corresponding author :reet.poudel@gmail.com

\begin{abstract}
Introduction: Children and adolescent form significant group of patients in psychiatry. The aim of this study was to identify the prevalence and pattern of different disorders in children and adolescent attending psychiatry OPD.

Material And Method: Socio-economic and other data of subjects 19 year and younger visiting the Out Patient Department (OPD) of Department of Psychiatry, Universal College of Medical Sciences (UCMS), Bhairahawa, Nepal was collected from the OPD register retrospectively. The duration of the study was one year, from January 2016 to December 2016. Diagnosis was made using the ICD 10. Data was analyzed using Statistical Package for the Social Sciences (SPSS) version 21.0 for Windows.

Results: The total number of subjects enrolled for the study was 591. The mean age of the subject was 14.8 years $(S D=2.8)$. Male constituted $44.67 \%(n=264)$ of the subjects while female $55.33 \%(n=327)$. Majority of the subjects were from rural background (66\%). The most common diagnosis was epilepsy $(17.3 \%)$ followed by dissociative disorder $(14.6 \%)$ and primary headache $(11.8 \%)$ respectively. There was no statistically significant association of these major three disorders with age of the patient. Dissociative disorder was observed in 68 females compared to 18 males which was statistically significant $(p=0.001)$.
\end{abstract}

Conclusion: Children and adolescent visiting the psychiatry OPD are diagnosed with a variety of disorders.

Keywords: Child \& Adolescent, Psychiatry, Nepal

\section{INTRODUCTION}

According to World Health Organization (WHO) the worldwide prevalence of child and adolescent mental disorders is approximately $20 \% .{ }^{1}$ Half of all mental disorders start by the age of $14 .^{2}$ One in 6 child and adolescent have a psychiatric disorder at any time while 1 in 3have one or more psychiatric disorder by age 16. ${ }^{3}$ Child and adolescent mental disorders manifest themselves in various domains and in different ways. Onset of mental disorders at a young age may lead to continuing functional impairment in adult life. ${ }^{1,3}$ Children and adolescents with good mental health are able to achieve and maintain optimal psychological and social functioning and well-being. ${ }^{4}$

Children and adolescent (19 years or younger) ${ }^{5}$ constitute $45.97 \%$ of the population of Nepal. ${ }^{6}$ As this represents a significant proportion of the population, mental health is of paramount importance for them in this part of the world. Low and middle income countries including Nepal lacks a system of mental health services 
for children and adolescent. They face various challenges including discrimination, stigma and isolation including lack of adequate health care facilities and educational opportunities.1,4

Various studies have been conducted in Nepal related to child and adolescent mental disorders. Children and adolescent visiting psychiatry outpatient department (OPD) are diagnosed with a wide range of disorders including epilepsy, mood disorders, psychotic disorders, dissociative disorders and headache; to name a few. The aim of the present study was to identify the prevalence and pattern of different disorders in children and adolescent attending psychiatry OPD.

\section{MATERIAL AND METHOD}

The present study was conducted at Department of Psychiatry, Universal College of Medical Sciences (UCMS), Bhairahawa, Nepal. The duration of the study was one year, from January 2016 to December 2016. All the subjects of age 19 year and younger visiting the psychiatry OPD were enrolled for the study. Socio-demographic profile and other details of individual patients were collected from the OPD register retrospectively. Diagnosis was made using the $\mathrm{ICD}^{7}{ }^{7}$. Data was analyzed using Statistical Package for the Social Sciences (SPSS) version 21.0 for Windows.

\section{RESULT}

The total number of subjects enrolled for the present study was 591 among which 56 (9.5\%) did not receive an ICD 10 diagnosis for mental disorder. The mean age of the subjects was 14.8 years $(\mathrm{SD}=2.8)$.

Table 1 shows the sociodemographic profile of the subjects. Male constituted $44.67 \%(n=264)$ of the subjects while female $55.33 \% \quad(n=327)$. Majority of the subjects were from rural background $(66 \%)$ and $91.9 \%$ of the subjects were Hindu by religion.

Table 2 shows the distribution of subjects based on age group and diagnosis. More than $96 \%$ $(n=568)$ of the subjects in our study were adolescents. More than fifty percent of the subjects were from 16-19 years age group, followed by $40.4 \%$ from $11-15$ years and $8.3 \%$
Table 1: Distribution of Socio-Demographic Characteristics

\begin{tabular}{|l|l|l|l|}
\hline \multicolumn{2}{|l|}{ Characteristics } & Frequency & Percentage \\
\hline \multirow{4}{*}{ Sex } & Male & 264 & \\
\cline { 2 - 4 } & Female & 327 & $44.7 \%$ \\
\hline \multirow{3}{*}{$\begin{array}{l}\text { Place of } \\
\text { Residence }\end{array}$} & Urban & 184 & $55.3 \%$ \\
\cline { 2 - 4 } & Rural & 390 & $31.1 \%$ \\
\cline { 2 - 4 } & India & 17 & $66 \%$ \\
\hline \multirow{5}{*}{\begin{tabular}{l} 
Religion \\
\cline { 2 - 4 }
\end{tabular}} & Hindu & 543 & $2.9 \%$ \\
\cline { 2 - 4 } & Muslim & 34 & $51.9 \%$ \\
\cline { 2 - 4 } & Christian & 7 & $1.2 \%$ \\
\cline { 2 - 4 } & Buddhist & 7 & \\
\hline
\end{tabular}

from 6-8 years age group. Subjects of age 5 years and less constituted $0.5 \%$. The most common diagnosis was epilepsy (17.3\%) followed by dissociative disorder (14.6\%) and headache $(11.8 \%)$ respectively. There was no statistically significant association of these three disorders with age of the patient. Psychotic disorders including acute and transient psychotic disorder and schizophrenia was found in $14.7 \%$ of the subjects. Dissociative disorder and anxiety disorder was more common in the younger subjects (11-15 years) compared to older subjects (16-19 years). Mood disorders were diagnosed in $16.75 \%$ of the subjects.

Table 3 shows the distribution of subjects based on diagnosis and sex. Dissociative disorder was observed in 68 females compared to 18 males which was statistically significant $(\mathrm{p}=0.001)$. 
Table 2: Distribution of Subjects According to Diagnosis \& Age

\begin{tabular}{|c|c|c|c|c|c|c|}
\hline \multirow[t]{2}{*}{ Diagnosis } & \multicolumn{4}{|c|}{ Age Range in years; $\mathrm{N}$} & \multirow[t]{2}{*}{ Total $(\%)$} & \multirow{2}{*}{$\begin{array}{c}\mathrm{p} \\
\text { value }\end{array}$} \\
\hline & $\begin{array}{c}0-5 \\
\text { years }\end{array}$ & $\begin{array}{c}6-10 \\
\text { years }\end{array}$ & $\begin{array}{l}11-15 \\
\text { years }\end{array}$ & $\begin{array}{l}16-19 \\
\text { years }\end{array}$ & & \\
\hline No diagnosis & 0 & 6 & 18 & 32 & $56(9.5)$ & \\
\hline Epilepsy & 0 & 7 & 40 & 55 & $102(17.3)$ & 0.749 \\
\hline Dissociative Disorder & 1 & 7 & 46 & 32 & $86(14.6)$ & 0.142 \\
\hline Primary Headache & 0 & 6 & 27 & 37 & $70(11.8)$ & 0.927 \\
\hline Mental Retardation & 0 & 3 & 5 & 4 & $12(2)$ & \\
\hline ATPD & 0 & 2 & 15 & 26 & $43(7.3)$ & \\
\hline Schizophrenia & 0 & 0 & 16 & 28 & $44(7.4)$ & \\
\hline RDD & 0 & 0 & 4 & 2 & $6(1)$ & \\
\hline Depression & 0 & 4 & 24 & 25 & $53(9)$ & \\
\hline BPAD & 1 & 0 & 9 & 18 & $28(4.7)$ & \\
\hline Mania & 0 & 1 & 4 & 13 & $18(3)$ & \\
\hline Alcohol abuse/dependence & 0 & 0 & 3 & 1 & $4(0.7)$ & \\
\hline Anxiety Disorder & 0 & 1 & 19 & 13 & $33(5.6)$ & \\
\hline Conduct Disorder & 0 & 5 & 1 & 2 & $8(1.4)$ & \\
\hline Opioid abuse/dependence & 0 & 0 & 0 & 1 & $1(0.2)$ & \\
\hline $\mathrm{ADHD}$ & 0 & 4 & 4 & 1 & $9(1.5)$ & \\
\hline Somatoform Disorder & 0 & 0 & 0 & 1 & $1(0.2)$ & \\
\hline Learning Disorder & 1 & 0 & 1 & 0 & $2(0.3)$ & \\
\hline Adjustment Disorder & 0 & 0 & 0 & 4 & $4(0.7)$ & \\
\hline Insomnia & 0 & 1 & 0 & 0 & $1(0.2)$ & \\
\hline OCD & 0 & 0 & 1 & 2 & $3(0.5)$ & \\
\hline Organic disorder & 0 & 1 & 0 & 0 & $1(0.2)$ & \\
\hline Anorexia Nervosa & 0 & 0 & 1 & 1 & $2(0.3)$ & \\
\hline ISH & 0 & 0 & 0 & 1 & $1(0.2)$ & \\
\hline Dhat syndrome & 0 & 0 & 1 & 1 & $2(0.3)$ & \\
\hline Acute stress reaction & 0 & 1 & 0 & 0 & $1(0.2)$ & \\
\hline $\operatorname{Total}(\%)$ & $3(0.5)$ & $49(8.3)$ & $239(40.4)$ & $300(50.8)$ & 591(100) & \\
\hline
\end{tabular}

\section{DISCUSSION:}

Majority of the subjects in the present study were female. Shakya et $\mathrm{al}^{8}$ and Risal et $\mathrm{al}^{9}$ observed female predominance in child psychiatry cases but the study sample included children of 0-18 years while in our study the sample age was 0-19 years. ${ }^{8}$ A study from India with same sample age of that of ours have supported our finding of female predominance in children and adolescent attending psychiatry
OPD. ${ }^{10}$ Other studies with similar methodology from Nepal ${ }^{11-13}$, India ${ }^{14}$ and Bangladesh ${ }^{15,16}$ have found male predominance in child psychiatry cases. The variation in the findings may be due to the difference in the sample age group enrolled in these studies. Some studies have included subjects upto 18 years of age, ${ }^{13}$ some 5 16 years of age, 16 and others; all the cases visiting child guidance clinic. ${ }^{12,14}$ 
Table 3: Distribution of Subjects According to Diagnosis \& Sex

\begin{tabular}{|c|c|c|c|c|}
\hline \multirow[t]{2}{*}{ Diagnosis } & \multicolumn{2}{|c|}{ Sex; N } & \multirow{2}{*}{ Total (\%) } & \multirow[t]{2}{*}{$\mathrm{p}$ value } \\
\hline & Male & Female & & \\
\hline No diagnosis & 23 & 33 & $56(9.5)$ & \\
\hline Epilepsy & 53 & 49 & $102(17.3)$ & 0.103 \\
\hline Dissociative Disorder & 18 & 68 & $86(14.6)$ & 0.001 \\
\hline Primary Headache & 28 & 42 & $70(11.8)$ & 0.346 \\
\hline Mental Retardation & 9 & 3 & $12(2)$ & \\
\hline ATPD & 22 & 21 & $43(7.3)$ & \\
\hline Schizophrenia & 28 & 16 & $44(7.4)$ & \\
\hline RDD & 4 & 2 & $6(1)$ & \\
\hline Depression & 27 & 26 & $53(9)$ & \\
\hline BPAD & 11 & 17 & $28(4.7)$ & \\
\hline Mania & 10 & 8 & $18(3)$ & \\
\hline Alcohol abuse/depn & 1 & 3 & $4(0.7)$ & \\
\hline Anxiety Disorder & 14 & 19 & $33(5.6)$ & \\
\hline Conduct Disorder & 3 & 5 & $8(1.4)$ & \\
\hline Opoid abuse/depn & 1 & 0 & $1(0.2)$ & \\
\hline ADHD & 6 & 3 & $9(1.5)$ & \\
\hline Somatoform Disorder & 0 & 1 & $1(0.2)$ & \\
\hline Learning Disorder & 0 & 2 & $2(0.3)$ & \\
\hline Adjustment Disorder & 2 & 2 & $4(0.7)$ & \\
\hline Insomnia & 1 & 0 & $1(0.2)$ & \\
\hline OCD & 0 & 3 & $3(0.5)$ & \\
\hline Organic disorder & 1 & 0 & $1(0.2)$ & \\
\hline Anorexia Nervosa & 0 & 2 & $2(0.3)$ & \\
\hline ISH & 0 & 1 & $1(0.2)$ & \\
\hline Dhat syndrome & 1 & 1 & $2(0.3)$ & \\
\hline Acute stress reaction & 1 & 0 & $1(0.2)$ & \\
\hline Total & $264(44.67 \%)$ & $327(55.33 \%)$ & $591(100 \%)$ & \\
\hline
\end{tabular}

The definition or the criteria for defining adolescence may differ among institutions and countries which also might have led to the variation in the sample age group for these studies and hence difference in finding of male or female predominance.

Adolescent (10-19 years) constituted $96 \%$ of the subjects whereas $50.8 \%$ of the subjects were from 16-19 years age group. High incidence of psychiatric disorders has been observed in upper extreme of age in child and adolescent in most of the studies. ${ }^{8-10}$ Jesmin et al found higher incidence of psychiatric disorder in 5-10 years age group but the sample included children from 5-16 years only. ${ }^{16}$ Similarly Chapagain et al found almost similar number of subjects in 0-9 year age group and 10-19 year age group. ${ }^{12}$

Majority of the Nepalese population being Hindu by religion, our finding of $91.9 \%$ of the subjects being Hindu was expected and it has 
been observed in almost all the studies from Nepal.8,9 Sixty six percent of the subjects belonged from rural background. Place of the residence of subjects has not been discussed in some studies $9,13,14$ while a single study from Nepal found higher number of subjects from semi-urban background ${ }^{8}$ tough it used a different mode of classification of place of residence than that of ours. A study from India found $74.8 \%$ of the child and adolescent from urban areas. ${ }^{10}$ This variation may be entirely due to the specific geographical location where the study was conducted.

The most common diagnosis was epilepsy $(17.3 \%)$ followed by dissociative disorder (14.6\%). Higher prevalence of epilepsy in child and adolescent was supported by studies from Nepal 8,9 and that of dissociative disorder by studies from both Nepal ${ }^{9,12}$ and India ${ }^{10}$. Primary headache $(\mathrm{PH})$ was diagnosed in $11.8 \%$ of the subjects and it was the third most common diagnosis in the present study. Shakya et el found high incidence of migraine headache $(17 \%)$ in their study which is in favour of our finding while other studies from Nepal ${ }^{12,13}$ and India ${ }^{14}$ observed the incidence of $\mathrm{PH}$ to be very less ranging from $0.94-1.5 \%$. Psychiatry OPD of UCMS handles neuropsychiatry cases like headache and epilepsy and majority of these cases are referred from other departments of the institution. Aich et al reported a total of 486 subjects visited the headache clinic in department of psychiatry at UCMS in a duration of three months alone. ${ }^{17}$ Thus a higher incidence of these disorders in our institution observed in the present study is justified.

Most of OPD based studies have found mental retardation (MR) as the most common diagnosis $^{12-15,18}$ while in the present study MR was observed in only $2 \%$ of the subjects. Heikura et $\mathrm{al}^{19}$ and Drews et $\mathrm{al}^{20}$ suggested that maternal/familial sociodemographic factors like socioeconomic disadvantage, maternal multiparity and pre-pregnancy maternal obesity are associated with variation in the incidence of MR. These factors might have contributed to the low prevalence of MR in the present study.

\section{CONCLUSION:}

The present study tried to analyze the sociodemographic profile and pattern of disorders with which children and adolescent visit psychiatry OPD. We found high attendance of neuropsychiatric disorders including epilepsy and primary headache in the subjects. Dissociative disorder and psychotic disorder were also observed in abundance. The authors hope that the present study will add more insight to the importance of child and adolescent psychiatry and will motivate other researchers to carry out studies in this sub-speciatity of psychiatry in community and national level.

\section{ACKNOWLEDGEMENTS: None}

\section{CONFLICT OF INTEREST: None}

\section{REFERENCES:}

1. World Health Organization. Atlas: Child and Adolescent mental health resources global concerns, implications for the future. Geneva: World Health Organization; 2005.

2. Kessler RC, Berglund $P$, Demler $O$, Jin $R$, Merikangas KR, Walters EE. Lifetime prevalence and age-of-onset distributions of DSM-IV disorders in the National Comorbidity Survey Replication. Arch Gen Psychiatry. 2005 Jun;62(6):593-602.

3. Costello EJ, Mustillo S, Erkanli A, Keeler G, Angold A. Prevalence and development of psychiatric disorders in childhood and adolescence. Arch Gen Psychiatry. 2003 Aug;60(8):837-44.

4. World Health Organization. Mental Health Policy and Service Guidance Package: Child and Adolescent Mental Health Policies and Plans. Geneva: World Health Organization; 2005.

5. WHO: Definition of key terms [Internet]. c2017. World Health Organization; [cited 2017 Dec16]. Available from: http://www.who.int/hiv/pub/guidelines/arv2013/i ntro//keyterms/en

6. Central Bureau of Statistics. 2015 Statistical Year Book. 15th ed. Kathmandu: Central Bureau of Statistics; 2016.

7. World Health Organization. The ICD-10 Classification of Mental and Behavioral Disorders Diagnostic Criteria for Research. Geneva: World Health Organization; 1993.

8. Shakya DR. Psychiatric morbidity profiles of child and adolescent. Journal of Nepal Paediatr Society. 2010;30(2):79-84.

9. Risal A, Sharma PP. Psychiatric illness in the paediatric population presenting to a psychiatry clinic in a tertiary care centre. Kathmandu University Medical Journal (KUMJ). 8(32):3753981.

10. Maan CG, Munnawar HMS, Heramani N, Lenin 
RK. Psychiatric morbidity profiles of child $\mathcal{E}$ adolescent patients attending the Regional Institute of Medical Sciences, Imphal. IOSR Journal of Dental and Medical Sciences. 2014;13(12):47-51.

11. Pokharel A, Ojha S, Koirala NR, Regmi S, Pradhan SN, Sharma V. A profile of children and adolescents referred by paediatricians to the child guidance clinic of Tribhuban teaching hospital. Nepal Journalof Psychiatry. 2001;2:116-22.

12. Chapagai M, Dangol KM, Tulachan P. A study of psychiatric morbidty amongst children attending $a$ child guidance clinic at a tertiary level teaching hospital in Nepal. Journal of Nobel Medical College. 2013;2(1:3):55-63.

13. Tulachan P, Chapagai M, Kunwar A, Sharma V. Psychiatric Morbidity Pattern in a Child and Adolescent Guidance clinic. Journal of Psychiatric Association of Nepal. 2011;1(1):20-3.

14. Chaudhury $S$, Prasad PL, Zacharias R, Madhusudan T, Saini R. Psychiatric Morbidity Pattern in a Child Guidance Clinic. Med journal, Armed Forces India. 2007 Apr;63(2):144-6.

15. Giasuddin NA, Diba SF. Pattern of Child and Adolescent Patients Attending Psychiatric Outpatient Department of the Mental Hospital in Bangladesh. Faridpur Medical College Journal. 2013;7(2):67-70.

16. Jesmin A, Mullick MSI M, Rahman KMZ, Muntasir MM. Psychiatric Disorders in Children and Adolescents Attending Pediatric Out Patient Departments of Tertiary Hospitals. Oman Med J. Oman Medical Specialty Board; 2016 Jul;31(4):258-62.

17. Gupta U, Aich TK, Verma AK. Psychiatric comorbidity in chronic migraine Patients: A hospital based study. Journal of Psychiatric Association of Nepal. 2014;3(1):3-9.

18. Chadda RK, Saurabh. Pattern of psychiatric morbidity in children attending a general psychiatric unit. Indian Journal of Pediatrics. 61(3):281-5.

19. Heikura $U$, Taanila A, Hartikainen A-L, Olsen P, Linna $S-L$, von Wendt $L$, et al. Variations in prenatal sociodemographic factors associated with intellectual disability: a study of the 20-year interval between two birth cohorts in northern Finland. Am J Epidemiol. 2008 Jan 15;167(2):169-77.

20. Drews CD, Yeargin-Allsopp M, Decouflé P, Murphy CC. Variation in the influence of selected sociodemographic risk factors for mental retardation. Am J Public Health. American Public Health Association; 1995 Mar;85(3):329-34. 